\title{
Chiller Controls-related Energy Saving Opportunities in
} Federal Facilities

\author{
Tom Webster, P.E. \\ Center for the Built Environment (CBE) \\ University of California, Berkeley CA \\ for \\ Lawrence Berkeley National Laboratory \\ Berkeley, CA \\ LBNL - 47649
}

January 2003

\section{INTRODUCTION}

Chillers are a significant component of large facility energy use. The focus of much of the development of chilled water systems in recent years has been on optimization of set point and staging controls, improvements in chiller design to increase efficiency and accommodate chlorofluorocarbon (CFC) refrigerant replacements. Other improvements have been made by upgrading controls to the latest digital technologies, improving access and monitoring via communications and sophisticated liquid crystal displays (LCD), more robust fault diagnostics and operating and maintenance information logging. Advances have also been made in how chiller plant systems are designed and operated, and in the diversity of chiller products that are available to support innovative approaches. As in many industries, these improvements have been facilitated by advances in, and lower costs for, enabling technologies, such as refrigerants, compressor design, electronics for controls and variable frequency drives (VFD).

Along with the improvements in electronics one would expect that advances have also been made in the functionality of unit controls included with chillers. Originally, the primary purpose of this project was to investigate the state of practice of chiller unit controllers in terms of their energy saving capabilities. However, early in the study it was discovered that advances in this area did not include incorporation of significantly different capabilities than had existed 10-15 years ago. Thus the scope has been modified to provide an overview of some of the basic controls-related energy saving strategies that are currently available along with guideline estimates of their potential and applicability. We have minimized consideration of strategies that could be primarily implemented via design practices such as chiller selection and plant design, and those that can only be implemented by a building management system (BMS). Also, since most of the floor space of federal buildings occurs in large buildings, we have focused on water-cooled screw and centrifugal chillers of 100 ton capacity and greater. However, the role of reciprocating and gas chillers (absorption and engine driven) is discussed briefly. 
Understanding the demographics of chiller deployment in the federal sector, state of practice of energy savings strategies and control features availability will help federal energy managers and program implementers to make informed decisions in support of energy saving performance contracting (ESPC) and other programs.

\section{CHILLERS IN THE FEDERAL SECTOR}

\subsection{CHILLER SUPPLY ISSUES}

There are approximately 10,000 centrifugal and screw chillers produced in the US each year out of a total of approximately 23,000 for all types (1996 data). The four major HVAC equipment manufacturers (Trane, Carrier, York, and McQuay) provide the majority of these large tonnage machines. [1] A large fraction of these are replacements for an existing population of about 80,000 centrifugal chillers that have been installed over the last 40 years [2] in US commercial buildings. Note that about half of the total production is for screw and centrifugal machines which are 100 ton and larger.

Natural gas-fired cooling recently has enjoyed a significant growth in popularity. Sales of gas-fired chillers in the U.S. have increased by about 20 percent per year from 1988 to 1996, although the total percentage of these chillers remains small. As users become more familiar with the technology, and the convergence of gas and electricity providers continues, this trend is likely to accelerate. Table 1 illustrates the growth in chiller production since 1990 .

Table 1 - Chiller Annual Production

\begin{tabular}{|l|c|c|}
\hline \multicolumn{1}{|c|}{ Chiller types } & 1990 Annual Production & 1996 Annual Production \\
\hline All Electric & 15,000 & 22,000 \\
\hline Gas Absorption & 175 & 600 \\
\hline Engine driven & 0 & 100 \\
\hline
\end{tabular}

Since the ban on CFC production starting in 1996, replacements were expected to significantly increase chiller production over the past few years, especially for federal facilities. Indications are, however, that replacements are running well behind the rate anticipated. One reason for this delay in federal facilities has to do with procurement practices. These practices have been revised with the issuance of the DOE-GSA Chiller Basic Ordering Agreement (BOA) that is being implemented as part of the Federal Supply Schedule (FSS) [3, 4].

\subsection{Federal Chiller Demographics}

Using the results of the 1993 Federal Buildings Supplemental Study (FBSS) [5] performed by the Energy Information Agency (EIA) for three federal regions (Regions 3, $6,9)$, the demographics of chillers in federal facilities have been estimated. Tables 2 and 3 show results from this study in terms of the percentages and floor space of buildings with chillers. Table 4 shows the results of this study extrapolated to a national scale 
assuming that the percentages found for the three regions are applicable to the entire (adjusted) population of 76,000 buildings represented in EIA's Commercial Buildings Energy Consumption Survey (CBECS) [6] database.

The FBSS study differs from CBECS in two major ways: 1) only buildings greater than $10,000 \mathrm{ft}^{2}$ were included in the FBSS survey, and 2) certain Principal Building Activity (PBA) types were excluded from the FBSS study (e.g., warehouses, religious buildings). We believe that these assumptions have negligible impact on our study of chillers since chillers are not typically found in the excluded buildings. Although a detailed comparison to CBECS data has not been made, we believe that the demographics of federal buildings are somewhat different than for commercial buildings at large. The CBECS database totals were adjusted for these assumptions before the percentages were applied. ${ }^{1}$ The data in these tables is broken down into the following building size categories:

$$
\begin{array}{ll}
\text { Small } & 10,000 \text { to } 50,000 \mathrm{ft}^{2} \\
\text { Medium } & 50,000 \text { to } 200,000 \mathrm{ft}^{2} \\
\text { Large } & 200,000 \mathrm{ft}^{2} \text { and larger }
\end{array}
$$

Table 2 - Demographics - Percentage of all Federal Buildings (Regions 3,6,9)

\begin{tabular}{|l|c|c|c|c|c|c|c|c|}
\hline & \multicolumn{2}{|c|}{$\begin{array}{c}\text { All } \\
\text { Fed Buildings } \\
\text { (based on } \\
\text { FBSS sample) }\end{array}$} & \multicolumn{2}{|c|}{$\begin{array}{c}\text { Buildings with } \\
\text { Chillers }\end{array}$} & \multicolumn{2}{c|}{$\begin{array}{c}\text { Buildings with } \\
\text { chillers less } \\
\text { than 10 yrs old }\end{array}$} & $\begin{array}{c}\text { Buildings with } \\
\text { chillers } \\
\text { greater than } \\
\text { 10 yrs old }\end{array}$ \\
\hline & $\#$ & $\mathrm{ft}^{2}$ & $\#$ & $\mathrm{ft}^{2}$ & $\#$ & $\mathrm{ft}^{2}$ & $\#$ & $\mathrm{ft}^{2}$ \\
\hline Small & $77 \%$ & $33 \%$ & $19 \%$ & $9 \%$ & $8 \%$ & $4 \%$ & $10 \%$ & $5 \%$ \\
\hline Medium & $19 \%$ & $32 \%$ & $7 \%$ & $14 \%$ & $3 \%$ & $6 \%$ & $4 \%$ & $8 \%$ \\
\hline Large & $3 \%$ & $35 \%$ & $2 \%$ & $21 \%$ & $0 \%$ & $4 \%$ & $1 \%$ & $15 \%$ \\
\hline All buildings & $\mathbf{1 0 0} \%$ & $\mathbf{1 0 0} \%$ & $\mathbf{2 8 \%}$ & $\mathbf{4 5 \%}$ & $\mathbf{1 2 \%}$ & $\mathbf{1 5 \%}$ & $\mathbf{1 6 \%}$ & $\mathbf{2 8 \%}$ \\
\hline
\end{tabular}

i.e., $19 \%$ of the number of buildings and $9 \%$ of total floor space of all federal buildings are small buildings served by chillers

Table 3 - Demographics - Percentage of Building Size Category (Regions 3,6,9)

\begin{tabular}{|l|c|c|c|c|c|c|}
\hline & \multicolumn{2}{|c|}{$\begin{array}{c}\text { Buildings with } \\
\text { Chillers }\end{array}$} & \multicolumn{2}{|c|}{$\begin{array}{c}\text { Buildings with } \\
\text { chillers less } \\
\text { than 10 yrs old }\end{array}$} & $\begin{array}{c}\text { Buildings with } \\
\text { chillers } \\
\text { greater than } \\
10 \text { yrs old }\end{array}$ \\
\hline & $\#$ & $\mathrm{ft}^{2}$ & $\#$ & $\mathrm{ft}^{2}$ & $\#$ & $\mathrm{ft}^{2}$ \\
\hline Small & $25 \%$ & $29 \%$ & $11 \%$ & $13 \%$ & $13 \%$ & $15 \%$ \\
\hline Medium & $38 \%$ & $44 \%$ & $15 \%$ & $19 \%$ & $21 \%$ & $23 \%$ \\
\hline Large & $61 \%$ & $61 \%$ & $13 \%$ & $12 \%$ & $44 \%$ & $44 \%$ \\
\hline
\end{tabular}

\footnotetext{
${ }^{1}$ Note that total percentages may not add correctly due to rounding, exclusion of minor factors, and minor anomalies in the data.
} 
i.e, $25 \%$ of small buildings have chillers; $44 \%$ of medium building floor area is served by chillers. 
Table 4 - Demographics - Number of Buildings and Floor Area Served by Chillers in Federal Buildings (National estimate)

\begin{tabular}{|c|c|c|c|c|c|c|c|c|}
\hline & \multicolumn{2}{|c|}{$\begin{array}{c}\text { All } \\
\text { Federal Buildings } \\
\text { (FBSS sample criteria) }\end{array}$} & \multicolumn{2}{|c|}{$\begin{array}{l}\text { Buildings with } \\
\text { Chillers }\end{array}$} & \multicolumn{2}{|c|}{$\begin{array}{l}\text { Buildings with } \\
\text { chillers Less } \\
\text { than } 10 \text { yrs old }\end{array}$} & \multicolumn{2}{|c|}{$\begin{array}{l}\text { Buildings with } \\
\text { chillers Greater } \\
\text { than } 10 \text { yrs old }\end{array}$} \\
\hline & $\# \times 10^{3}$ & $\mathrm{ft}^{2} \times 10^{9}$ & $\# \times 10^{3}$ & $\mathrm{ft}^{2} \times 10^{9}$ & $\# \times 10^{3}$ & $\mathrm{ft}^{2} \times 10^{9}$ & $\# \times 10^{3}$ & $\mathrm{ft}^{2} \times 10^{9}$ \\
\hline Small & 46 & 0.47 & 11 & 0.13 & 4.9 & 0.06 & 6.0 & 0.07 \\
\hline Medium & 11 & 0.46 & 4.4 & 0.20 & 1.8 & 0.09 & 2.5 & 0.11 \\
\hline Large & 1.8 & 0.50 & 1.1 & 0.30 & 0.23 & 0.06 & 0.81 & 0.22 \\
\hline Total & 59 & 1.4 & 16 & 0.64 & 6.9 & 0.210 & 9.3 & 0.40 \\
\hline
\end{tabular}

Table 4 shows a total of 59,000 federal buildings fit the FBSS sampling criteria. As noted above, we believe that these represent the sample most likely to utilize central chillers. The results shown in Table 4 indicate that over 16,000 buildings have central chillers, about 9000 of which have chillers over ten years old. It also shows that central chillers serve about $640 \mathrm{M}$ square feet of floor area (45\% of all federal building floor area). The following additional conclusions can be drawn from these tables:

- While the number of buildings varies from a high of $77 \%$ for small buildings to $3 \%$ for large buildings, the distribution on a floor space basis is equal for all categories at about 33\%.

- Large buildings with chillers make up $21 \%$ of federal sector floor space and since large buildings make up 35\% of all federal floor space, central chillers serve $61 \%$ of federal sector large building floor space.

- Small buildings are likely served by reciprocating or screw chillers, (especially those greater than 10 years old). Many of these will be air-cooled. The mid- to high-end large building range is served predominately by water-cooled centrifugal chillers.

\section{CHILLER PLANT CONTROL STRATEGIES}

There are numerous examples of chiller systems that were designed without much forethought to optimization of performance, are oversized for the actual loads, or are poorly commissioned. In fact, one of the greatest opportunities for significant savings over and above upgrading to a more efficient machine or implementing controls related strategies is by careful, thoughtful design/sizing and the implementation of good commissioning procedures. ${ }^{2}$ Reference [7] shows the types of performance improvements that are possible just due to the numerous selection parameters that are

\footnotetext{
${ }^{2}$ For example, some facilities have 24 hour loads (labs and datacenters). If the plant is not designed to accommodate these types of loads (i.e., by using variable speed chillers or properly staging a small auxiliary (pony) chiller) these small loads will increase the energy usage dramatically by causing the plant to run at low loads during evenings and weekends.
} 
applicable. Replacement offers an opportunity to maximize energy savings even more by utilizing current low $\mathrm{kW} /$ ton machines, better controls, and resizing to meet known load conditions better. The performance improvement due to using modern machines with nominal $\mathrm{kW} /$ ton ratings of 0.5 to 0.6 versus those of the past that operated at 0.75 to 1.25 $\mathrm{kW} /$ ton argues for considering replacement as a primary strategy for maximizing savings. However, it should be noted that even when good design and sizing is used, savings can still be derived from implementation of the controls related strategies outlined below.

As noted above, the following discussion is focused on large building water-cooled centrifugal and screw chiller systems. Smaller systems with air-cooled machines are not discussed explicitly although some of the strategies (e.g., chilled water supply (CHWS) reset) are still applicable.

Controls-related savings strategies in chiller plants can be implemented by one or more of the following devices: 1) unit controllers, 2) chiller plant control panels (CPP) or 3) building management system (BMS) panels. Items 2 and 3 can be interfaced to the chillers and other plant equipment directly and/or by a communications interface to the chiller unit controller. In most systems energy savings strategies are implemented via a BMS. These strategies can either be implemented independently or in combination and with or without optimization. Optimum control involves consideration of tradeoffs between two or more system components. In this report we include the following as optimization strategies:

- Smart start/stop (SSS) - starting and stopping chillers at beginning and end of the day based on historical load anticipation.

- Optimized reset (OR) - optimization of entering condenser water temperature (ECWT) or CHWS reset strategies, which includes consideration of tower (fan and sump pump) and chilled water pumping energy tradeoffs with chiller performance improvements, respectively.

- $\quad$ Plant total energy sequencing (TP) - combined optimization of condenser and evaporator sub-systems and chiller sequencing strategies.

- Real time (RT) - total system (chilled water plant plus air handling system), based on real-time simulations of the entire system. [8]

Other control strategies such as demand limiting and soft loading are designed to reduce peak demand and do not impact energy use significantly unless comfort is compromised. They do, however, produce energy cost savings where demand charges are applied. (In the future explicit demand charges may be replaced by real time pricing strategies). Table 5 provides a summary of various control-related functions available in modern chiller plants. 
Table 5 - Chiller Plant Controls Overview

\begin{tabular}{|c|c|c|c|c|c|}
\hline Control Strategy & $\begin{array}{l}\text { Optimiz } \\
\text { ation }^{1}\end{array}$ & $\begin{array}{l}\text { Type of } \\
\text { Impact }\end{array}$ & $\begin{array}{c}\text { Estimated } \\
\text { relative } \\
\text { Energy Impact }\end{array}$ & $\begin{array}{l}\text { Function } \\
\text { typically } \\
\text { resides in } \\
\end{array}$ & Remarks \\
\hline Speed control & $\mathrm{TP}$ & Energy & High & $\mathrm{U} / \mathrm{CPP} / \mathrm{BMS}$ & $\begin{array}{l}\text { VFDs on chillers, pumps and tower fan } \\
\text { motors can have a substantial effect on } \\
\text { energy consumption. VFDs for chillers } \\
\text { are only applicable to centrifugal } \\
\text { machines; this technology is not yet } \\
\text { available on screw machines for the } \\
\text { HVAC market. }\end{array}$ \\
\hline Soft loading & NA & Demand & Neg. & $\mathrm{U}$ & Ramping of load upon chiller start. \\
\hline $\begin{array}{l}\text { Demand } \\
\text { limiting }\end{array}$ & NA & Demand & Varies & $\mathrm{U} / \mathrm{CPP} / \mathrm{BMS}$ & $\begin{array}{l}\text { Set demand limits to avoid exacerbating } \\
\text { peak demand charges. This can save } \\
\text { energy and demand by not meeting the } \\
\text { zone loads thus causing zone } \\
\text { temperatures to creep above their control } \\
\text { set point. }\end{array}$ \\
\hline CHWS reset & OR & Energy & Low & $\mathrm{U} / \mathrm{CPP} / \mathrm{BMS}$ & $\begin{array}{l}\text { Reset of CHWS temperature upward as } \\
\text { load decreases (e.g., } 44 \text { to } 55^{\circ} \mathrm{F} \text { ). }\end{array}$ \\
\hline ECWT reset & OR & Energy & Varies & CPP/BMS & $\begin{array}{l}\text { Reset of ECWT downward as outside } \\
\text { conditions and tower loading permits. }\end{array}$ \\
\hline Free cooling & $\mathrm{TP}$ & Energy & Varies & CPP/BMS & $\begin{array}{l}\text { Used primarily where cooling loads are } \\
\text { high during cold weather conditions. }\end{array}$ \\
\hline Heat recovery & $\mathrm{TP}$ & Energy & Varies & CPP/BMS & $\begin{array}{l}\text { Used primarily when there are } \\
\text { significant combined heating and cooling } \\
\text { loads. }\end{array}$ \\
\hline Tight deadband & NA & Control & Low & $\mathrm{U}$ & Tight CHWS control. \\
\hline $\begin{array}{l}\text { Sequencing/ } \\
\text { balancing }\end{array}$ & $\mathrm{TP}$ & Energy & Medium & CPP/BMS & $\begin{array}{l}\text { Sequencing multiple chillers has a } \\
\text { significant impact on how chillers are } \\
\text { loaded and therefore overall energy use. }\end{array}$ \\
\hline $\begin{array}{l}\text { Inhibit start } \\
\text { (additional } \\
\text { chillers) }\end{array}$ & NA & Demand & Neg. & CPP/BMS & $\begin{array}{l}\text { Inhibiting of chiller startup until there is } \\
\text { sufficient load to be carried by the new } \\
\text { chiller. }\end{array}$ \\
\hline $\begin{array}{l}\text { Temperature } \\
\text { override }\end{array}$ & $\mathrm{TP}$ & Energy & Low & CPP/BMS & $\begin{array}{l}\text { Override of pre-programmed schedules } \\
\text { based on outside or space temperature } \\
\text { input. }\end{array}$ \\
\hline $\begin{array}{l}\text { Scheduling } \\
\text { (including smart } \\
\text { stop/start) }\end{array}$ & SSS & Energy & Low-Medium & CPPBMS & $\begin{array}{l}\text { Control of operating hours with or } \\
\text { without optimized start/stop has a direct } \\
\text { impact on energy consumption. }\end{array}$ \\
\hline
\end{tabular}

${ }^{1}$ Typical way optimization is applied when it is used.

${ }^{2} \mathrm{U}=$ Unit controller; CPP = Chiller plant panel; BMS = Building Management System; Neg. = Negligible 
Due to the wide potential for application and increasing popularity of use we have selected three strategies from those listed in Table 5 for a more detailed assessment. These three strategies are; 1) ECWT reset, 2) CHWS reset, 3) chiller variable speed control. Although not strictly a control strategy per se since VFD hardware is involved, variable speed drives for chillers require sophisticated control algorithms in the centrifugal chiller unit controller that allow the machine to ride the surge line to maximize COP under all load conditions. Although the savings are impressive (see below), the cost effectiveness may be minimized due to the high cost of the drives, which can add as much as $25-50 \%$ to the cost of a chiller. VFD prices continue to decrease, however, allowing this strategy to be used more widely.

\subsection{Reset Performance Estimates}

Detailed performance and cost effectiveness estimates are beyond the scope of this report; provided here is an assessment of potential savings based on review of the literature, vendor product information, and discussions with vendor technical personnel.

Table 6 shows the range of percentage savings in $\mathrm{kW} /$ ton for CHWS and ECWT reset strategies for fixed and variable speed chiller drives (based on single implementation). [9]

Table 6 - Chiller $\mathrm{kW} /$ ton Percentage Savings Per Degree $\left({ }^{\circ} \mathrm{F}\right)$ of Reset

\begin{tabular}{|l|c|c|}
\hline & Fixed Speed & VFD \\
\hline CHWS Reset & $0.5-.75 \%$ & $2-3 \%$ \\
\hline ECWT reset & $0.75-1.25 \%$ & $1.5-2.0 \%$ \\
\hline
\end{tabular}

\subsubsection{ECWT reset}

This strategy allows for the ECWT to be reset downward (over a typical range of 20$30^{\circ} \mathrm{F}$ ) as weather conditions permit; i.e., when outdoor wet bulb lowers, usually during low load conditions. The use of ECWT reset has increased recently (from almost negligible use 10-15 years ago) primarily due to the recognition of its benefits and support for this strategy from ARI standards.

Figure 1 shows part load performance curves for York chillers ${ }^{3}$ with and without ECWT reset (assumes minimum of $55^{\circ} \mathrm{F}$ ECWT that is only achievable with some designs) and with a VFD. Note that the savings for ECWT reset alone (compare top two curves) are relatively low ${ }^{4}$ compared to the savings when ECWT reset is combined with a VFD. For example, at $40 \%$ load the $\mathrm{kW} / \mathrm{ton}$ is about $50 \%$ of that of a fixed speed, fixed ECWT design; $\mathrm{kW} /$ ton at these conditions is in the range of 0.2 for a nominal $0.6 \mathrm{~kW} /$ ton chiller.

${ }^{3}$ These are example curves. Performance varies by manufacturer, chiller construction (i.e. numbers of stages) and chilled water setpoint.

${ }^{4}$ Although there is a significant difference below about $60 \%$ load, the actual annual savings will be determined by the annual load profile. 
There are six ways tower leaving water temperature (i.e., ECWT) is commonly controlled:

1) Fixed at or near design (i.e., $75-85^{\circ} \mathrm{F}$ ) - minimizes tower energy but saves no chiller energy;

2) Coldest possible for given wet bulb and tower capacity - minimizes chiller energy, but maximizes tower energy;

3) Wet bulb plus $5^{\circ} \mathrm{F}$ or constant approach ${ }^{5}$ - attempts to "optimize” tower vs. chiller energy.

4) Fixed set point below cooling tower design approach - a simple strategy that balances chiller and tower energy usage. The rule of thumb is for the tower leaving set point to be at or near the design outdoor wet-bulb temperature.

5) Dual-set point - a strategy for systems with two-speed or pony motors on the cooling towers. In this strategy a high set point is provided for the tower when one or more fans are at full speed.

6) Optimal control - Optimized reset of ECWT to minimize the combined tower and chiller energy use.

Estimates vary as to the annual savings achievable with ECWT reset applied alone to fixed speed chillers and it appears to depend on the type of reset strategy used. Optimal ECWT control is estimated to save 4-5\% annually over strategies 1 and 2. [10] [11] Strategy 3 appears to be slightly less effective than Strategy 1. Strategies 4 and 5 can often be used to achieve $90 \%$ of the savings of optimal control. They have several distinct advantages over the reset scheme in item 3: a) they are easier to program; b) they are intuitive to the operator; c) they are easier to commission. [12]

\footnotetext{
${ }^{5}$ Tower approach $=$ tower leaving temperature $($ ECWT) minus tower air entering wet bulb
} 


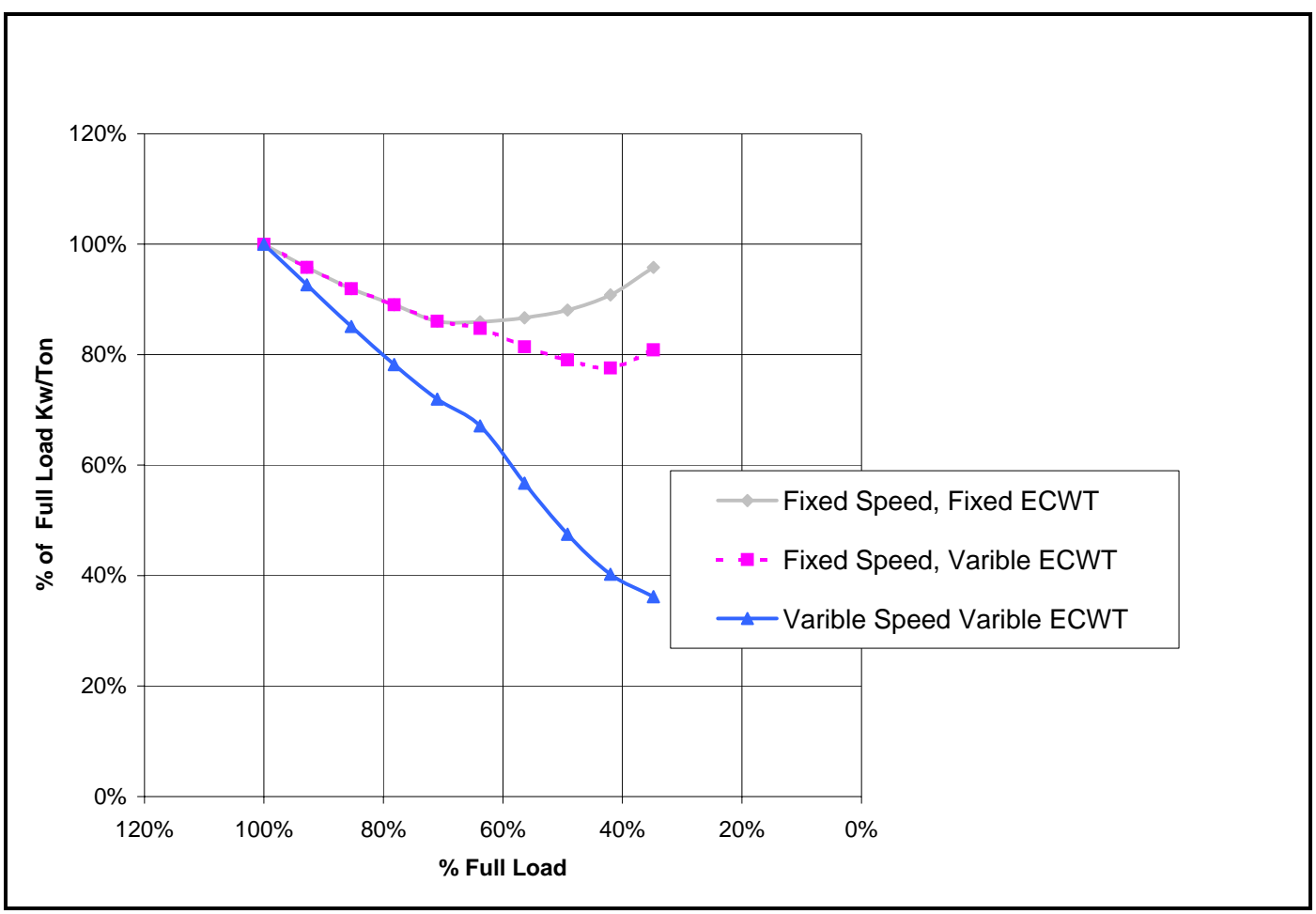

Figure 1 - Impact on Chiller Performance of ECWT Reset and Variable Speed Drives

\subsubsection{CHWS reset}

This strategy entails reset of chiller leaving water temperature over a range of about $10^{\circ} \mathrm{F}$ (depending on system design) as load decreases. This strategy is typically implemented today by resetting CHWS temperature based on coil valve position; i.e., temperature is adjusted to keep the most open coil control valve at say $90 \%$ open. Other methods include reset based on outside air temperature or chilled water return temperature. This latter strategy is not effective when low delta $\mathrm{T}$ problems emerge at low loads. Likewise it may not yield savings when variable speed pumps are used since the pump speed and power will increase as flow increases. It will almost always yield savings for fixed speed pumping. [13] Table 6 shows that for variable speed chillers, the improvement in chiller performance per degree of reset is larger for CHWS reset than for ECWT reset. The overall effect, however, may not be as great since the range of reset is lower, about $10^{\circ} \mathrm{F}$ vs. as much as $20-30^{\circ} \mathrm{F}$ for ECWT (i.e., $65-55^{\circ} \mathrm{F}$ minimum, respectively). Although not shown, performance curves for CHWS reset would be similar to those shown in Figure 1. Annual savings are estimated to be in the range of 5-10\%. [14] Care must be exercised in using this strategy since greater coil temperatures can reduce latent capacity of the coils and compromise humidity control. However, humidity control at the air handler is usually less of an issue under low load conditions so that the impact on comfort of increased coil temperatures is minimized. 


\subsection{VARIABLE SPEED CHILLERS}

The use of variable speed drives on chillers is increasing due to lower costs, better reliability, and the recent availability of drives larger than $400 \mathrm{Hp}$. Three of the four major chiller vendors offer VFD options for their centrifugal products. The addition of a VFD can have a dramatic effect on energy savings as discussed above. Various calculations show [14] [15] that compared to fixed speed chillers using ECWT reset, annual savings for a variable speed chiller alone can be in the range of $20-30 \%$ with total plant annual savings of approximately $10-20 \%$. Note that for typical plants, only one VFD chiller may be required to handle low load conditions and for topping service.

\subsection{COMMENTS}

Unfortunately, little information is available as to the overall impact on annual performance of any of the reset strategies cited above and even less for combined strategies and/or optimization; the savings figures shown above are estimates based on review of a variety of sources rather than from a comprehensive study.

Although total plant energy optimization has been commercially available since 1987 (e.g., York's CPP), it appears that overall it was used very little in the past and is only now receiving increased emphasis. Similarity, RT optimization, although developed in the late 1980's, has not been used extensively most likely due to high first cost, complexity, and low cost effectiveness.

Overall it can be concluded that reset strategies must be compared to optimized control to determine their effectiveness; blind application of reset strategies are likely to produce little if any savings. Only the addition of a VFD is assured to consistently produce significant savings.

It also is clear from this study that chiller unit controllers do not support plant wide energy saving control strategies. This is understandable in that the unit controllers are dedicated to supporting many machine related control functions and operating sequences as well as providing diagnostics and user interface support in a more or less standard way. The numerous variations in chiller plant designs would result in a unique unit controller for each project and would compromise the integrity of the operational algorithms and complicate technical support.

It makes little difference whether a BMS or CPP implements the strategies since it is possible with current technology to implement virtually all functions in a CPP. In fact, most CPPs are derived from BMS technology provided by the chiller vendor. Chiller vendors claim that their panels are better able to implement plant wide control since they understand the equipment better, and in fact the trend is toward chiller vendor supplied panels vs. BMS vendor implementation. 


\section{FEDERAL SECTOR POTENTIAL}

We can gain some insight about the potential for savings in the federal sector when we combine the demographics with the savings impact from the strategies being reviewed. As shown earlier, application of controls-related savings strategies depend on the availability of plant wide controls capabilities; unit controllers typically contain little or no capabilities in this regard. Therefore, a key factor in the ability to implement these strategies is whether the system is installed with a CPP or BMS. While we have no information on the penetration of CPPs in federal buildings, the FBSS database does allow us to identify buildings with chillers and a BMS. Table 7 shows a breakdown for federal buildings with chillers with and without a BMS on the premises. Although a detailed analysis of savings potential is beyond the scope of this report, study of Table 8 provides an overview of the potential of, and different approaches to, retrofit strategies for each of the cases shown. The total potential energy savings could be derived from this study with a more detailed estimate of the savings for each case. For example, buildings with old chillers and no BMS might be good candidates for a complete chiller retrofit combined with a CPP (application potential $=29 \%$ of total floor spaced served by chillers). On the other hand, newer chillers with a BMS might only require an upgrade in logic to implement controls related energy savings strategies (application potential $=11 \%$ of chilled floor space).

Table 7 - Demographics of Buildings with Chillers and a BMS

\begin{tabular}{|l|c|c|c|c|c|c|c|c|}
\hline & \multicolumn{2}{|c|}{$<\mathbf{1 0}$ yrs, BMS } & \multicolumn{2}{c|}{$\begin{array}{c}\text { 10 yrs, no } \\
\text { BMS }\end{array}$} & \multicolumn{2}{c|}{$>\mathbf{1 0}$ yrs, BMS } & \multicolumn{2}{c|}{$\begin{array}{c}\text { 10 yrs, no } \\
\text { BMS }\end{array}$} \\
\hline & $\#$ & $\mathrm{ft}^{2}$ & $\#$ & $\mathrm{ft}^{2}$ & $\#$ & $\mathrm{ft}^{2}$ & $\#$ & $\mathrm{ft}^{2}$ \\
\hline Small* & $3 \%$ & $2 \%$ & $35 \%$ & $37 \%$ & $20 \%$ & $17 \%$ & $33 \%$ & $33 \%$ \\
\hline Medium & $12 \%$ & $13 \%$ & $24 \%$ & $23 \%$ & $18 \%$ & $16 \%$ & $37 \%$ & $37 \%$ \\
\hline Large & $14 \%$ & $14 \%$ & $6 \%$ & $6 \%$ & $46 \%$ & $48 \%$ & $25 \%$ & $23 \%$ \\
\hline Overall** & $\mathbf{6 \%}$ & $\mathbf{1 1 \%}$ & $\mathbf{3 0 \%}$ & $\mathbf{1 8 \%}$ & $\mathbf{2 1 \%}$ & $\mathbf{3 1 \%}$ & $\mathbf{3 4 \%}$ & $\mathbf{2 9} \%$ \\
\hline
\end{tabular}

* Small, medium, large values indicate percentages within the given building size category; e.g., $12 \%$ of all medium sized buildings have a BMS and a chiller less than 10 years old.

** Overall refers to all buildings with chillers; e.g., $29 \%$ of the floor space of buildings with chillers is served by systems with a no BMS and a chiller greater than 10 years old.

Discussions with chiller and controls vendors indicate that the penetration of these strategies has been, and continues to be, evolutionary rather than revolutionary. In general it appears that we can roughly divide the time horizon into two periods, prior to 10-15 years ago and within the last $10-15$ years. In general the following conclusions about these periods can be drawn:

1. Prior to $10-15$ years:

- $\quad$ Reset strategies were used primarily on the largest projects and were provided primarily by BMS providers (except for York CPS applications). 
- The use of VFDs was very low and they were not factory mounted

- The use of CPPs was very low

- There was negligible application of optimization

2. During last $10-15$ years:

- Increasing and more routine (say medium to high penetration) application of reset strategies via CPPs or BMSs in most projects (large and small); currently being split between chiller vendor supplied CPPs and BMS supplied solutions at about $20 \%$ and $80 \%$, respectively.

- Low but increasing use of VFDs in chillers (and pumps and tower fan motors).

- Increasing but low application of optimization.

Table 8 provides an overall summary of the potential and suggested strategy for each of four possible cases.

Table 8 - Controls Related Savings Strategy Potential Summary

\begin{tabular}{|l|c|c|l|l|}
\hline Opportunity & $\begin{array}{c}\text { \% of total } \\
\text { federal } \\
\text { building floor } \\
\text { space }\end{array}$ & $\begin{array}{c}\text { \% of chiller } \\
\text { served floor } \\
\text { space }\end{array}$ & Assumed current status & \multicolumn{1}{|c|}{ Suggested Strategy } \\
\hline $\begin{array}{l}\text { Old Chiller, } \\
\text { no BMS }\end{array}$ & $13 \%$ & $29 \%$ & $\begin{array}{l}\text { Fixed speed, high kW/ton, } \\
\text { CFC chiller, with } \\
\text { negligible penetration of } \\
\text { reset strategies, VFDs, and } \\
\text { optimization }\end{array}$ & $\begin{array}{l}\text { Replace/upgrade chiller, } \\
\text { add CPP with reset logic } \\
\text { including optimization. }\end{array}$ \\
\hline $\begin{array}{l}\text { Old chiller, } \\
\text { with BMS }\end{array}$ & $14 \%$ & $31 \%$ & $\begin{array}{l}\text { Fixed speed, high kW/ton, } \\
\text { CFC chiller with low } \\
\text { penetration of reset } \\
\text { strategies, and negligible } \\
\text { penetration of VFDs and } \\
\text { optimization. }\end{array}$ & $\begin{array}{l}\text { Replace/upgrade chiller and } \\
\text { add reset logic with } \\
\text { optimization via BMS } \\
\text { upgrade. }\end{array}$ \\
\hline $\begin{array}{l}\text { New chiller, } \\
\text { no BMS }\end{array}$ & $8 \%$ & $18 \%$ & $\begin{array}{l}\text { Medium penetration of low } \\
\text { kW/ton, non-CFC chillers, } \\
\text { low/medium penetration of } \\
\text { reset strategies, VFDs and } \\
\text { negligible use of } \\
\text { optimization. }\end{array}$ & $\begin{array}{l}\text { Install CPP with reset } \\
\text { strategies using } \\
\text { optimization. }\end{array}$ \\
\hline $\begin{array}{l}\text { New chiller, } \\
\text { with BMS }\end{array}$ & $11 \%$ & $\begin{array}{l}\text { Medium penetration of } \\
\text { low kw/ton, non-CFC } \\
\text { chillers; low penetration } \\
\text { of VFDs; } \text { medium/high } \\
\text { penetration of reset } \\
\text { strategies, low use of } \\
\text { optimization. }\end{array}$ & $\begin{array}{l}\text { Consider upgrade to VFD, } \\
\text { employ optimized control } \\
\text { via BMS }\end{array}$ & \\
\hline
\end{tabular}


Note that about $60 \%$ of chilled floor space is served by chillers greater than 10 years old roughly split equally among buildings with and without a BMS. Note also the small percentage of systems that are less the 10 years old combined with a BMS. This indicates that the majority floor space, $~ 80 \%$ of chiller served space and $35 \%$ of all federal building floor space, is served by systems with no BMS and/or have chillers greater than 10 years old. These are the best candidates for providing significant savings by employing chiller controls and chiller retrofit strategies.

\section{CONCLUSIONS \& RECOMMENDATIONS FOR FURTHER STUDY}

In almost all buildings with chillers there is an opportunity for savings. The potential varies with age of chiller and availability of a BMS. The only case that has little opportunity is for those buildings with newer chillers that also have a BMS. This is a small fraction of the population, less than $10 \%$ of federal floor space. There is a much greater opportunity for significant performance improvements in all other cases; i.e., buildings with no BMS and newer chillers, and buildings with older chillers with and without a BMS. These latter categories make up about $80 \%$ of buildings with chillers.

It has been found that reset strategies are commonly applied but without optimization. Applied individually without a VFD and without optimization results in little or no savings, except possibly for ECWT reset. Optimization is critical to insure savings, especially when CHWS reset is used with variable speed pumping. However, chillers using a VFD, especially combined with ECWT reset, can produce dramatic savings.

Further research is necessary to provide a comprehensive assessment of performance potential for various control options especially when they are combined with one another. Such a study may require that new capabilities be incorporated in simulation programs to overcome limitations that currently exist. 


\section{REFERENCES}

[1] Fryer, L., "Electric Chiller Buyer's Guide: Water-Cooled Centrifugal and Rotary Screw Chillers,” Tech Update TU-97-7, Esource, July 1997.

[2] Esource, "Commercial Space Cooling and Air Handling Technology Atlas," Technology Atlas TA-SC-95, Esource, June 1995.

[3] Federal Supply Service, G. S. A., "100 to 2000 Ton Commercial Centrifugal and Rotary Screw Water-Chilling Packages," November 15, 1996.

[4] Kale, S. H., J. Guice, "DOE-GSA Chiller Basic Ordering Agreement," November 15, 1996.

[5] EIA, "Federal Buildings Supplemental Survey 1993," SR/EMEU/95-02, Energy Information Administration, USDOE, 1995.

[6] EIA, "CBECS: Commercial Buildings Characteristics 1995," DOE/EIA-E-0109, Energy Information Administration (EIA), USDOE, August 1997.

[7] Bellenger, L. G. and J. D. Becker, "Selecting High-Efficiency Centrifugal Chillers: A System Approach," Heating/Piping/Air-conditioning, July 1996, p. 41.

[8] Cumali, Z., "Gobal Optimization of HVAC System Operations in Real Time," ASHRAE Transactions, No. DA-88-23-1, 1988.

[9] Baird, J., Personal Communication, October 29 1998, Senior Chiller Development Engineer, York International.

[10] Braun, J. E., S. A. Klein, J. W. Mitchell, and W. A. Beckman, "Applications of Optimal Control to Chilled Water Systems without Storage," ASHRAE Transactions, vol. 95 (1), October 1995, p. 652.

[11] Trane. How Much Does Tower Water Control Optimization Save. Trane Co., 1998. Available from: www.trane.com/commercial/library/v24a8.asp.

[12] Hydeman, M., Personal Communication, November 8, 2001, Principal, Taylor Engineering.

[13] Taylor, S., "Low Delta-T in New and Existing Chilled Water Plants," Taylor Engineering, 1998.

[14] Aitcheson, P., "Getting the Most Out of your Chiller," Energy Manager, January 1999, p. 26.

[15] York, "Update: Chiller-Plant Energy Performance," RPC 10M 197, York International Corp., 1997. 


\section{BIBLIOGRAPHY}

Austin, S. B., "Optimum chiller loading," ASHRAE Journal, July 1991, p. 40.

Beyene, A., "Performance Evaluation of Conventional Chiller Systems," ASHRAE Journal, June 1995, p. 36.

Braun, J. E., Mitchell, J.W., Klein, S.A., Beckman, W.A., "Models for Variable-speed Centrifugal Chillers,” Symposium NY-87-22-2, ASHRAE, 1987.

Braun, J. E., S. A. Klein, W. A. Beckman, , and J. W. Mitchell, "Methodolgies for Optimal Control of Chilled Water Systems Without Storage," ASHRAE Transactions, vol. 95 (1), No. October 1995, p. 652.

Carrier, "Application Guide: Flotronic System Manager," Carrier Corp., 1993.

Carrier, "Overview: Chillervisor System Manager III,” Carrier Corp., 1998.

Carrier, "Product Data: Series 30HX Chillers,” Form 30HX-3PD, Carrier Corp., 1997.

Cler, G. L., "Gas Chiller Buyer's Guide: Absorption and Engine-Driven Chillers," Tech Update TU-97-11, Esource, September 1997.

Cler, G. L., "Hybrid Chiller Plants Can Everyone Really Win?," Strategic Memo SM-965, Esource, May 1996.

Griffith, D. R., "Distribution Problems in Central Plant Systems," Heating/Piping/Air Conditioning, November 1987, p. 12.

Guice, J., Personal Communication, September 9 1998, Project Manager, Systematic Management Services, Inc.,

Hydeman, M. M., J. Cole, P. Ferber, and R. Winch, "Baseline Practices Survey: Commercial Chilled Water Plant Design,” CT-001-1998, Pacific Gas and Electric, October 1998.

Johnson, G. A., "Optimization Techniques for a Centrifugal Chiller Plant Using a Programmable Controller," Symposium HI-85-16 No. 1, ASHRAE, 1985.

Kaya, A., Sommer, A., "Energy Management of Chillers by Multilevel Control and Optimization," Transactions of the ASME, vol. 107, No. December, 1985.

Kintner-Meyer, M., Emery, A. F., "Cost-Optimal Analysis of Cooling Towers,” ASHARE Transactions, vol. 101, pt. 2.

Kujak, M., Personal Communication, October 28 1998, Consultant to Heatcraft,

Lau, A. S., Beckman, W.A., Mitchell, J.W., "Development of Computerized Control Strategies for a Large Chilled Water Plant,” Symposium CH-85-16 No. 3, ASHRAE, 1985.

McQuay, "MicroTech Chiller System Controller, Operation Manual,” Bulletin No. OM 127, McQuay International, 1997. 
Moe, J., "Controlling Multiple Reciprocating Water Chillers," Engineered Systems, January/February 1987, p. 50-55.

Saur, J. M., "Diagnosing Low Temperature Differential," ASHRAE Journal, June, 1989.

Schwedler, M., Personal Communication, October 27 1998, Senior Applications Engineer, Trane Co.

Spethmann, D. H., "Optimized Control of Multiple Chillers," Symposium HI-85-16 No. 2, ASHRAE, 1985.

Thielman, D. E., "Chiller Optimization by Energy Management Control Systems," ASHRAE Journal, November, 1983.

Trane, "CenTraVac Liquid Chillers,” CTV-DS-1, Trane Co., November 1997.

Trane, "Series R CenTraVac Rotary Liquid Chillers, 130-450 Tons,” RLC-DS-1, Trane Co., February 1994.

Tschirky, B., Personal Communication, November 6 1998, Sales Engineer, Yamas Co.,

York, "C.P.A. Chiller Plant Automation Specification,” Form 450.11-GS4, York International, 1998.

York, "Mellennium Centrifugal Chillers, 350-2000 Tons, HFC-134a,” Form 160.52-EG1, York International, 1998. 